\title{
PATTERNS OF PERIANAL FISTULA IN MAGNETIC RESONANCE IMAGING AND ITS USEFULNESS IN THEIR PRE-SURGICAL EVALUATION
}

\author{
Sebastian Varghese1, Krishna Chaitanya Nunna²
}

1DNB, Department of Radiodiagnosis, Dr. Somervell Memorial CSI Medical College and Hospital, Thiruvananthapuram, Kerala, India. ${ }^{2}$ MD, Department of Radiodiagnosis, Dr. Somervell Memorial CSI Medical College and Hospital, Thiruvananthapuram, Kerala, India.

\section{ABSTRACT}

\section{BACKGROUND}

Until recently, cross-sectional imaging had a limited role in the preoperative assessment of perianal fistulas. Magnetic resonance imaging (MRI) has been shown to be an effective and essential imaging method in the evaluation of fistula-in-ano and the multiplanar images acquisition has demonstrated to be extremely useful in the surgical planning. Considering its high reliability in the reproduction of perianal anatomy, allowing the characterization and classification of the fistula based on its relation with the pelvic diaphragm and the anal sphincter is contributing for a successful surgical approach and thus avoiding the disease recurrence. ${ }^{1}$

Aims and Objectives- The aim of this study is to describe the various patterns and grading of perianal fistulae in Magnetic Resonance Imaging (MRI) and to assess its diagnostic accuracy and usefulness in preoperative evaluation.

1. The type, number and extent of perianal fistula.

2. Fistulous tracts in relation to the sphincter complex, ischiorectal/ ischioanal fossa and levator ani plate and their MRI grading.

3. Patterns, locations and sides of external and internal openings.

4. Involvement of pelvic floor/ viscera.

5. Perianal abscess, horseshoe fistulas, ramifications, subcutaneous oedema and sinuses.

6. The diagnostic accuracy and usefulness of MRI in preoperative evaluation as compared with postoperative diagnosis.

\section{MATERIALS AND METHODS}

This prospective observational study was performed in the Department of Radiodiagnosis and Imaging, Dr. Somervell Memorial CSI Medical College, Karakonam in the period between January - July 2017. A total of 100 patients who presented to Surgical OPD of Dr. Somervell Memorial CSI Medical College, suspected of perianal disease were included for the purpose of the study.

\section{Inclusion Criteria}

Patients presenting to Surgical OPD of SM-CSI with signs and symptoms like-

1. Perianal discharge.

2. Pain.

3. Swelling.

4. Bleeding.

5. Diarrhoea.

6. Skin excoriation.

7. External opening

8. Patients with known Crohn's disease.

9. Patients with history of previous intervention and recurrence.

\section{Exclusion Criteria}

1. Patients not willing to participate in the study.

2. Claustrophobic patients.

3. Patients having any metallic/ electronic implants in the body.

\section{RESULTS}

- A total of 50 patients, who presented to Surgical OPD of SM-CSI, suspected of perianal disease were included for the purpose of the study.

- Maximum number of cases were observed in the age group of 31 - 40 years and minimum number of cases were observed in $<20$ years' age group. The youngest patient was of 18 years of age and the oldest was of 58 years.

- All cases are more common in males than females. About two-thirds of all the cases are having complaint of pain and swelling.

- Among all cases 86 cases were diagnosed by MRI as perianal fistula, 6 cases as sinus and 8 cases as abscess.

- Maximum number of cases of perianal fistula were observed in the age group of 31 - 40 years and no case of perianal fistula was observed in $<20$ years' age group. The youngest patient was of 25 years age and the oldest was of 58 years. Sinus and abscess cases were almost evenly distributed in all age groups.

- Among perianal fistula cases, $86 \%$ were male patients. All sinus cases were male patients and among abscess cases $75 \%$ were male patients.

- Among perianal fistulae cases, $76 \%$ cases are of low type.

- Among perianal fistulae cases, $23 \%$ cases are having ischiorectal/ ischioanal fossae involvement.

- $\quad$ Among perianal fistulae, $49 \%$ cases are of grade I $>$ followed by Grade II (28\%) $>$ Grade IV (11\%) $>$ Grade III $(7 \%)>$ Grade V (5\%). 
- $\quad 95 \%$ of fistulae cases and all cases of abscess were managed operatively, while conservative management was done in all sinus cases. Overall, $90 \%$ cases underwent operative management, while conservative management was done in $10 \%$ cases.

\section{CONCLUSION}

MRI is having excellent results in showing rectum, perianal region, internal and external anal sphincter, levator ani, ischiorectal and ischioanal region. It can show the relationship between fistula and the sphincteric mechanism and can describe the primary fistulous passage as well as the secondary ramification and associated abscess. Diagnostic accuracy of preoperative MRI as compared to postoperative diagnosis was found to be $97.77 \%$. Overall, sensitivity of preoperative MRI diagnosis is $97.7 \%$ with 95\% Confidence Interval between $86.7 \%$ - 99.8\%. The positive predictive value was found to be $100 \%$. So, we can conclude that with accuracy of $97.77 \%$ in this study high-spatial-resolution MR imaging is a highly accurate, rapid and non-invasive imaging technique for preoperative evaluation of perianal disease.

\section{KEY WORDS}

Perianal Fistula; Abscess; Levator ani; Ischiorectal Fossa.

HOW TO CITE THIS ARTICLE: Varghese S, Nunna KC. Patterns of perianal fistula in magnetic resonance imaging and its usefulness in their pre-surgical evaluation. J. Evolution Med. Dent. Sci. 2018;7(21):2621-2627, DOI: 10.14260/jemds/2018/589

\section{BACKGROUND}

A fistula is defined as an abnormal connection with passage way between two structures or organs or between an organ and the surface of the body. ${ }^{2}$ In case of perianal fistula, it is a connection between the anal canal and the skin of the perineum. It is an uncommon condition of the gastrointestinal tract, predominantly affecting young adults with higher frequency in men. ${ }^{3}$ It is an important illness because of its high morbidity rate and tendency towards recurrence. The most common presenting symptom is discharge, but local pain due to inflammation is also common. ${ }^{4}$

Until recently, cross-sectional imaging had a limited role in the preoperative assessment of perianal fistulas. Magnetic resonance imaging (MRI) has been shown to be an effective and essential imaging method in the evaluation of fistula-inano and the multiplanar images acquisition has demonstrated to be extremely useful in the surgical planning, considering its high reliability in the reproduction of perianal anatomy, allowing the characterisation and classification of the fistula based on its relation with the pelvic diaphragm and the anal sphincter, evaluating its extent and identifying foci of infection and contributing for a successful surgical approach and avoiding the disease recurrence.

\section{Aim}

The aim of this study is to describe the various patterns and grading of perianal fistulae in Magnetic Resonance Imaging (MRI) and to assess its diagnostic accuracy and usefulness in preoperative evaluation.

\section{Objectives}

1. The type, number and extent of perianal fistula.

2. Fistulous tracts in relation to the sphincter complex, ischiorectal/ ischioanal fossa and levator ani plate and their MRI grading.

'Financial or Other Competing Interest': None.

Submission 01-01-2018, Peer Review 06-05-2018,

Acceptance 12-05-2018, Published 21-05-2018.

Corresponding Author:

Krishna Chaitanya Nunna,

12-17-75/12, Sontivari Street,

Repalle, Guntur District-522265,

Andhra Pradesh, India.

E-mail: krishnachaitanya.nunna@gmail.com

DOI: $10.14260 /$ jemds $/ 2018 / 589$
3. Patterns, locations and sides of external and internal openings.

4. Involvement of pelvic floor/ viscera.

5. Perianal abscess, horseshoe fistulas, ramifications, subcutaneous oedema and sinuses.

6. The diagnostic accuracy and usefulness of MRI in preoperative evaluation as compared with postoperative diagnosis.

\section{MATERIALS AND METHODS}

\section{Study Design}

A prospective observational study. Study by convenient sample size since the duration of the study was few months. The patients were selected by convenience sample size.

\section{Duration of Study}

January 2017 to July 2017

\section{Study Setting}

Department of Radiodiagnosis, Dr. Somervell Memorial CSI Medical College, Karakonam.

\section{Study Population}

Patients suspected of perianal disease presenting to Surgical OPD of Dr. Somervell Memorial CSI Medical College, Karakonam.

\section{Sample Size}

The study comprised a total of 100 patients.

\section{Inclusion Criteria}

Patients Presenting to Surgical OPD of SM-CSI with Signs and Symptoms like-

1. Perianal discharge.

2. Pain.

3. Swelling.

4. Bleeding.

5. Diarrhoea

6. Skin excoriation.

7. External opening

8. Patients with known Crohn's disease.

9. Patients with history of previous intervention and recurrence. 


\section{Exclusion Criteria}

1. Patients not willing to participate in the study.

2. Claustrophobic patients.

3. Patient having any metallic/ electronic implants in the body.

\section{Methodology}

All the patients fulfilling the above-mentioned criteria were evaluated clinically and data were recorded in a pre-devised proforma. After completion of case history and clinical examination, the patients were subjected to MRI. Further the patients were subjected to operative or conservative management was decided by the Surgeon on the basis of MRI findings and patient's compliance (Age, severity of associated morbidities, patient's acceptance). Then the MRI diagnosis was correlated with postoperative diagnosis in operated cases to evaluate the usefulness of preoperative MRI.

\section{Statistical Analysis}

Data were analysed using computer software. Statistical Package for Social Sciences (SPSS) version 17. Data are expressed in frequency and percentage. Diagnostic accuracy of preoperative MRI was evaluated against postoperative diagnosis.

\author{
Sample Size \\ $\mathrm{n}=4 \mathrm{pq} / \mathrm{l}^{2}$ \\ $\mathrm{p}=$ proportion of having perianal disease in population \\ $\mathrm{q}=1-\mathrm{p}$ \\ $\mathrm{l}=20 \%$ of $\mathrm{p}=$ permissible error in the estimation of $\mathrm{P}$ \\ Alpha error- $5 \%$ \\ The actual value of $p$ is $1 / 10000$ \\ For the present calculation ' $p$ ' is assumed as $50 \%(0.5)$ \\ Hence, $\mathrm{p}=0.5 ; \mathrm{q}=1-0.5$; \\ $\mathrm{l}=20 \times 0.5 / 100=0.1 ; \mathrm{l}^{2}=0.01$ \\ $\mathrm{n}=4 \times 0.5 \times 0.5 / 0.01=1 / 0.01=100$ \\ Hence, $\mathrm{n}=100$ \\ Patients attending the surgical OPD during the period of \\ study were included.
}

\section{RESULTS}

- A total of 100 patients who presented to Surgical OPD of SM-CSI suspected of perianal disease were included for the purpose of the study. The sample size was also done at conveniences.

- Maximum number of cases were observed in the age group of 31 - 40 years and minimum number of cases were observed in $<20$ years' age group. The youngest patient was of 18 years age and the oldest was of 58 years.

- $\quad$ All cases are more common in males than females. About two-thirds of all the cases are having complaint of pain and swelling.

- Among all cases 86 cases were diagnosed by MRI as perianal fistula, 6 cases as sinus and 8 cases as abscess.

- Maximum number of cases of Perianal fistula were observed in the age group of 31 - 40 years and no case of perianal fistula was observed in $<20$ years' age group. The youngest patient was of 25 years age and the oldest was of 58 years. Sinus and abscess cases were almost evenly distributed in all age groups.
- Among perianal fistula cases, $86 \%$ were male patients. All sinus cases were male patients and among abscess cases $75 \%$ were male patients.

- More than $80 \%$ of cases of perianal fistula, more than $60 \%$ cases of sinus and $25 \%$ of cases of abscess were having complaint of discharge.

- History of previous intervention and recurrence is present in less than $33 \%$ of cases of perianal fistula, whereas there was no history of previous intervention and recurrence in cases of sinus and abscess.

- Among perianal fistulae cases, $23 \%$ cases are having ischiorectal/ ischioanal fossa involvement.

- Levator ani and pelvic floor/ viscera involvement is not seen in $95 \%$ of cases of perianal fistulae and all cases of sinus.

- $\quad$ Among perianal fistulae, $49 \%$ cases are of Grade I > followed by Grade II (28\%) > Grade IV (11\%) > Grade III $(7 \%)>$ Grade V $(5 \%) .{ }^{5}$

- 86 cases were having external and internal openings, hence they were diagnosed as fistulae and 6 cases were having only external opening, hence they were diagnosed as sinuses.

- External opening is located posteriorly in $79 \%$ of fistulae and $67 \%$ of abscess cases.

- External opening is more on right side than on left side in cases of sinuses, whereas external opening is more on left side than on the right side in cases of fistulae.

- Perianal abscess is not seen in more than $90 \%$ cases of perianal fistula and all cases of sinus.

- Among perianal fistulae cases, $76 \%$ cases are of low type. ${ }^{6}$

- Among perianal fistulae cases, $83 \%$ cases are single.

- Among perianal fistulae cases, 9\% cases are having horseshoe fistula.

- Among perianal fistulae cases, $40 \%$ cases are having ramifications.

- Subcutaneous oedema is absent in about $80 \%$ cases of perianal fistula and all cases of sinus, whereas subcutaneous oedema is seen in all cases of abscess.

- $\quad 95 \%$ of fistulae cases and all cases of abscess were managed operatively, while conservative management was done in all sinus cases. Overall, 90\% cases underwent operative management, while conservative management was done in $10 \%$ cases.

\section{For Perianal Fistula}

- Sensitivity $=100 \%, 95 \% \mathrm{CI}=21.9 \%-98.6 \%$

- Positive predictive value $=100 \%, 95 \% \mathrm{CI}=89.3 \%-100 \%$

- $\quad$ Negative predictive value $=0.0 \%$

- $\quad$ Accuracy $=91.1 \%$

For Abscess

- $\quad$ Sensitivity $=75 \%, 95 \% \mathrm{CI}=89.3 \%-100 \%$

- $\quad$ Positive predictive value $=100 \%, 95 \% \mathrm{CI}=30.9 \%-100 \%$

- $\quad$ Negative predictive value $=0.0 \%$

- $\quad$ Accuracy $=75.0 \%$

Overall

- $\quad$ Sensitivity $=97.7 \%, 95 \% \mathrm{CI}=86.7 \%-99.8 \%$

- Positive predictive value $=100 \%, 95 \% \mathrm{CI}=91.9 \%-100 \%$

- $\quad$ Negative predictive value $=0.0 \%$

- $\quad$ Accuracy $=97.7 \%$ 
Overall accuracy of preoperative MRI diagnosis as compared to postoperative diagnosis was found to be $97.77 \%$

\section{DISCUSSION}

MRI imaging of perianal fistulae is based on the inherent high soft tissue contrast resolution and the multiplanar display of anatomy.7 MRI is having excellent results in showing rectum, perianal region, internal and external anal sphincter, levator ani, ischiorectal or ischioanal region. It can show the relationship between fistula and the sphincteric mechanism and can describe the primary fistulous passage as well as the secondary ramification and associated abscess. ${ }^{8}$ The surgical exploration without previous MRI diagnosis can be difficult due to the presence of fibrosis and oedema. ${ }^{9}$

In this study, diagnostic accuracy of Magnetic Resonance Imaging (MRI) as compared with postoperative diagnosis was evaluated.

A total of 100 cases were evaluated in this study. Out of total 100 cases diagnosed by MRI, 90 cases underwent surgery and 10 cases were managed conservatively. The operative or conservative management was decided by the surgeon on the basis of MRI findings and patient's compliance (Age, severity of associated morbidities, patient's acceptance).

Out of total 90 operated cases, in 88 cases the preoperative MRI diagnosis was accurately matched with the postoperative diagnosis. In 2 cases the MRI diagnosis was given as perianal abscess only, but during surgery patient was found to have perianal fistula. So the diagnostic accuracy of preoperative MRI as compared to postoperative diagnosis was found to be $88 / 90 \times 100=97.77 \%$. Overall Sensitivity of preoperative MRI diagnosis is $97.7 \%$ with 95\% Confidence Interval between $86.7 \%$ - 99.8\%. The positive predictive value was found to be $100 \%$. True negative cases could not be found out as Surgeons could not afford to proceed to operation with negative MRI diagnosis (i.e. normal study) at the expense of true negative cases. Therefore, Specificity could not be assessed in this study.

Among all 100 cases, 86 cases were diagnosed by MRI as perianal fistula, 6 cases as sinus and 8 cases as abscess. Maximum number of cases of Perianal fistula were observed in the age group of $31-40$ years and no cases were observed in $<20$ years' age group. The youngest patient was of 25 years age and the oldest was of 58 years. Sinus and abscess cases were almost evenly distributed in all age groups. All cases are more common in males $(86 \%)$ than females (14\%). Among perianal fistula cases, $86 \%$ were male patients. All sinus cases were male patients and among abscess cases $75 \%$ were male patients.

More than $60 \%$ of cases of perianal fistula and sinus and all cases of abscess were having complaint of pain. More than $80 \%$ of cases of perianal fistula, more than $60 \%$ cases of sinus and $25 \%$ of cases of abscess were having complaint of discharge. Swelling is present in less than $35 \%$ of cases of perianal fistula and all cases of abscess, whereas no swelling was present in sinus cases.

History of previous intervention and recurrence is present in less than $33 \%$ of cases of perianal fistula, whereas there was no history of previous intervention and recurrence in cases of sinus and abscess.
Perianal abscess is present in less than $10 \%$ cases of perianal fistula and is absent in all cases of sinus. Subcutaneous oedema is seen in $21 \%$ cases of perianal fistula and all cases of abscess, whereas it is absent in all cases of sinus.

86 cases were having external and internal openings, hence they were diagnosed as fistulae; 6 cases were having only external opening, hence they were diagnosed as sinuses. The location of external opening is posteriorly in $79 \%$ of fistulae and $67 \%$ of abscess cases. In cases of fistulae, external opening is more on left side than on the right side, whereas in cases of sinuses external opening is more on right side than on left side.

Among perianal fistulae cases $76 \%$ cases are of low type, $83 \%$ cases are single, $40 \%$ cases are having ramifications, $9 \%$ cases are having horseshoe fistula, levator ani and pelvic floor/ viscera involvement is seen in 5\% cases and $23 \%$ cases are having ischiorectal/ ischioanal fossae involvement.

According to St. James' University Hospital MR imaging Classification of perianal fistula, $49 \%$ cases are of Grade I followed by Grade II (28\%), then Grade IV (11\%), then Grade III (7\%) and lastly Grade V (5\%). ${ }^{5}$

$95 \%$ of fistulae cases and all cases of abscess were managed operatively, while conservative management was done in all sinus cases. Overall, 90\% cases underwent operative management, while conservative management was done in remaining $10 \%$ cases.

Most common operation done was Fistulectomy, which was done in $80 \%$ of fistulae cases and incision and drainage was done in $75 \%$ of abscess cases. ${ }^{10}$

Postoperative correlation as compared to preoperative MRI diagnosis was seen in all cases of perianal fistulae and $75 \%$ of abscess cases.

We believe that our study has several strengths. First very few such studies have been done on Indian population. So, our study will be very useful in reference to the Indian population. Second, it proves the results of previous studies and further strengthens the importance of MRI in evaluation of Perianal disease. ${ }^{11}$ Thirdly, the fact is that our study is a prospective evaluation of the cases.

Few pitfalls were also there in the study, as the sample size was relatively small. Another limitation was that there was a single observer interpretation. So, we did not assess interobserver variability in the evaluation of these findings and in the final assessments. Then the specificity also could not be assessed in this study.

\section{Advantages of Magnetic Resonance Imaging}

Clinical examination can often be difficult because of induration and inflammation in patients with anal sepsis. ${ }^{12}$ At MR imaging, identification and localisation of the entire fistula including the external opening, the primary track, secondary tracks, abscesses and the internal opening can be done, which is essential for fistula classification and treatment. ${ }^{13}$ Its advantage is that fistulae and abscesses are visible without the need to apply any contrast medium. ${ }^{14}$

MR imaging has a critical role in helping determine the proper treatment of perianal fistulas, because treatment strategies should be according to the type of perianal fistula and the degree of involvement of surrounding pelvic 
structures. MR imaging may become particularly useful in surgery of recurrent or complex anal fistulas. ${ }^{14}$

\section{Limitations of Magnetic Resonance Imaging}

The use of MRI requires a radiologist with experience in pelvic anatomy. Failure to align MRI images with the anal canal axis is a common error. A limitation of MRI is that it is unable to identify the dentate line. 15 The use of MRI also adds a considerable cost component to the patient's care. In addition, some patients have relative or absolute contraindications to MRI including those with specific implanted devices such as pacemakers and certain cerebral aneurysm clips. Imaging will also be limited in patients who are claustrophobic. ${ }^{15}$

\section{Limitation of the Study}

Due to short duration of the study, convenient sample size was followed. Thus sample size was also calculated by convenience. The results of the study cannot be generalised due to the potential bias resulting from the sample size estimation.
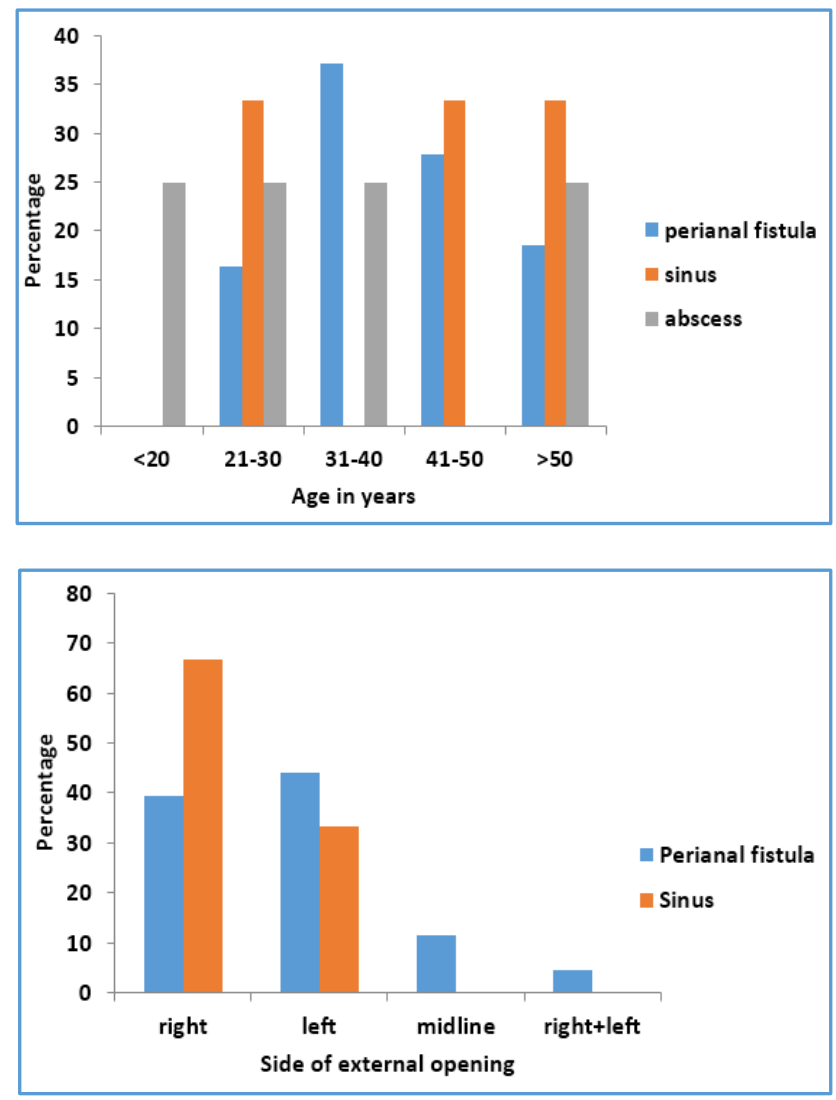

\begin{tabular}{|c|c|c|c|c|}
\hline Postoperative & \multicolumn{2}{|c|}{ Perianal Fistula } & \multicolumn{2}{c|}{ Abscess } \\
\cline { 2 - 5 } Correlation & $\mathbf{N}$ & $\mathbf{0}$ & $\mathbf{N}$ & $\%$ \\
\hline Yes & 82 & 100.0 & 6 & 75.0 \\
\hline No & 0 & .0 & 2 & 25.0 \\
\hline Total & $\mathbf{8 2}$ & $\mathbf{1 0 0 . 0}$ & $\mathbf{8}$ & $\mathbf{1 0 0 . 0}$ \\
\hline Table 1. Accuracy of Preoperative MRI Diagnosis as \\
compared to Postoperative Diagnosis \\
\hline
\end{tabular}
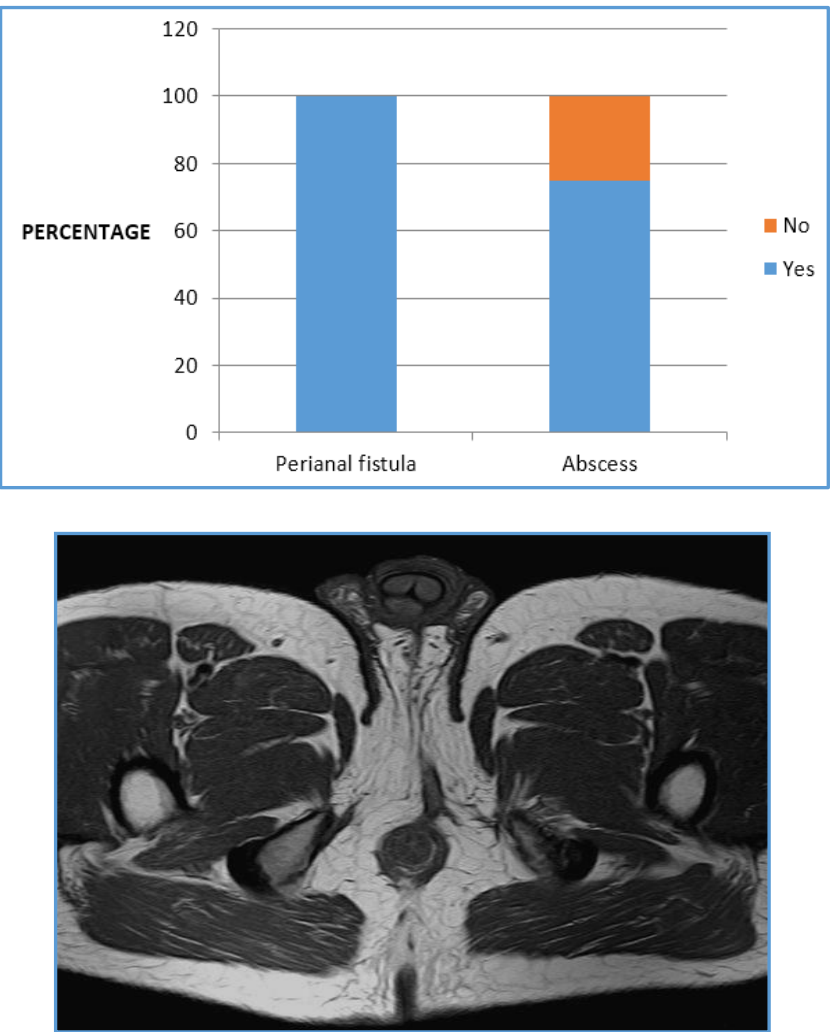

Figure 1. T1W Axial Image-Grade 3: Trans-sphincteric Fistula

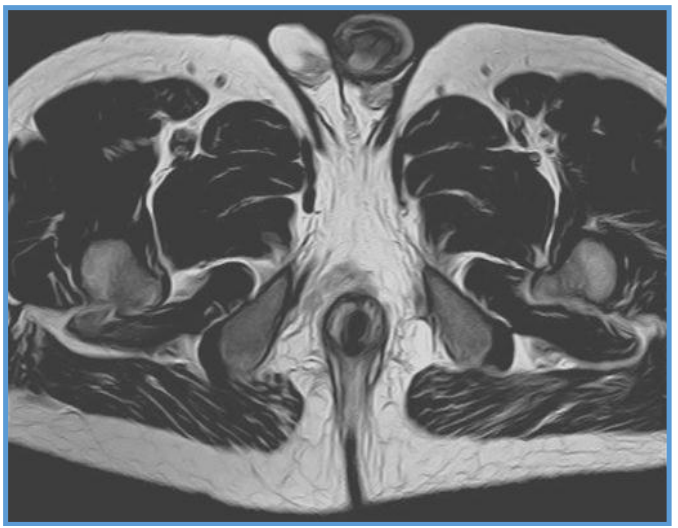

Figure 2. T2W Axial Image- Horseshoe Fistula

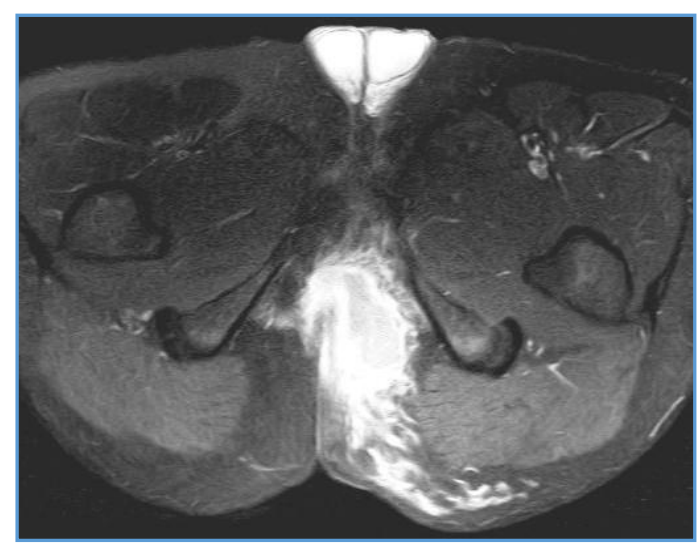

Figure 3. T1W SPIR Axial Image-Perianal Abscess 


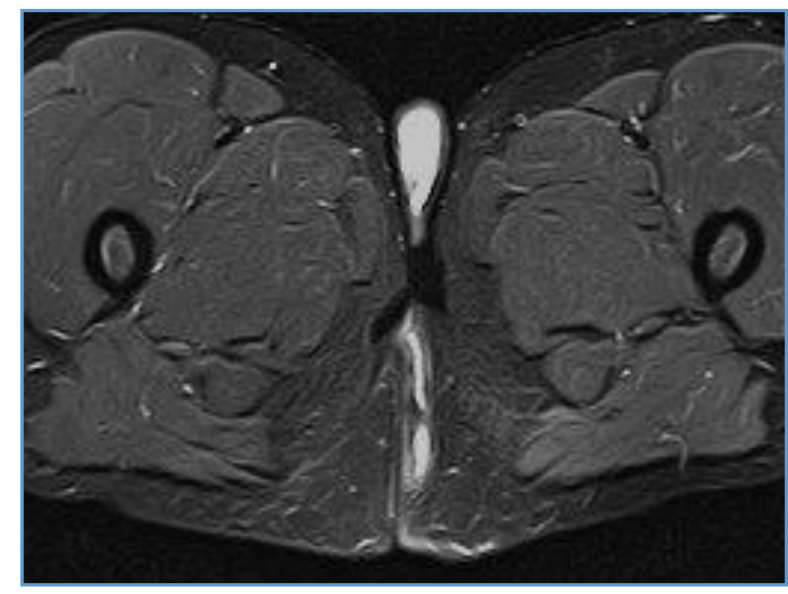

Figure 4. Stir Axial Image- Grade 2: Intersphincteric Fistula with Secondary Track

\section{CONCLUSION}

In this study, description of various patterns and grading of perianal fistulae in Magnetic Resonance Imaging (MRI) and its diagnostic accuracy as compared with postoperative diagnosis and its usefulness was evaluated.

In this study a total of 100 cases were evaluated, who came to Surgical OPD of Dr. Somervell Memorial CSI Medical College, Karakonam from January 2017 to July 2017 with complaints of perianal pain, discharge, swelling etc. and clinically suspected to be having perianal fistula, sinus or perianal abscess and referred to the Department of Radiodiagnosis, Dr. Somervell Memorial CSI Medical College for multiplanar high-spatial-resolution MR imaging of perianal region.

So out of total 100 cases, 86 cases were diagnosed as perianal fistula, 6 cases were diagnosed as sinus and remaining 8 cases were diagnosed as abscess by preoperative MR imaging.

Maximum number of cases of Perianal fistula were observed in the age group of 31 - 40 years and no cases were observed in < 20 years' age group. Sinus and abscess cases were almost evenly distributed in all age groups. All cases are more common in males than females.

Most cases of perianal fistula and sinus and all cases of abscess were having complaint of pain. ${ }^{16}$ Most cases of perianal fistula and sinus and few cases of abscess were having complaint of discharge. ${ }^{17}$ Swelling is present in less than one-third of cases of perianal fistula and all cases of abscess, whereas no swelling was present in sinus cases. 18

History of previous intervention and recurrence is present in less than one-third of cases of perianal fistula, whereas there was no history of previous intervention and recurrence in cases of sinus and abscess.

Perianal abscess is present in few cases of perianal fistula and is absent in all cases of sinus. Subcutaneous oedema is seen in few cases of perianal fistula and all cases of abscess, whereas it is absent in all cases of sinus.

The location of external opening is posteriorly in more than two-third cases of fistulae and abscess. In cases of fistulae, external opening is more on left side, whereas in cases of sinuses it is more on right side.

Among perianal fistulae cases, more than three-fourth of the cases are of low type and single, less than half of the cases are having ramifications, few cases are having horseshoe fistula and levator ani and pelvic floor/viscera involvement and one-fourth cases are having ischiorectal/ischioanal fossae involvement.

According to St. James' University Hospital MR imaging classification of perianal fistula, about half of the cases are of Grade I followed by Grade II, then Grade IV, then Grade III and lastly Grade V.

$95 \%$ of fistulae cases and all cases of abscess were managed operatively, while conservative management was done in all sinus cases. ${ }^{19}$

Out of total 100 cases diagnosed by MRI, 90 cases underwent surgery and 10 cases were managed conservatively. Most common operation done was Fistulectomy. The operative or conservative management was decided by the Surgeon on the basis of MRI findings and patient's compliance.

Out of total 90 operated cases, in 88 cases the preoperative MRI diagnosis was accurately matched with the postoperative diagnosis. In 2 cases the MRI diagnosis was given as perianal abscess only, but during surgery patient was found to have perianal fistula.

So, the diagnostic accuracy of preoperative MRI as compared to postoperative diagnosis was found to be $97.77 \%$. Overall Sensitivity of preoperative MRI diagnosis is 97.7\% with 95\% Confidence Interval between $86.7 \%$ $99.8 \%$. The positive predictive value was found to be $100 \%$.

True negative cases could not be found out, as Surgeons could not afford to proceed to operation with negative MRI diagnosis (i.e. normal study) at the expense of true negative cases. Therefore, Specificity could not be assessed in this study.

So, we can conclude that with accuracy of $97.77 \%$ in this study, high-spatial-resolution MR imaging is a highly accurate, rapid and non-invasive imaging technique for preoperative evaluation of perianal disease.

\section{REFERENCES}

[1] Sofic A, Beslic S, Sehovic N, et al. MRI in evaluation of perianal fistulae. Radiol Oncol 2010;44(4):220-7.

[2] Agur AMR, Lee MJ, Grant JCB. Grant's Atlas of Anatomy. $10^{\text {th }}$ edn. London, UK: Lippincott Williams and Wilkins 1999.

[3] Sainio P. Fistula-in-ano in a defined population. Incidence and epidemiologic aspects. Ann Chir Gynaecol 1984;73(4):219-24.

[4] Sinnatamby CS. Last's Anatomy: regional and applied. $10^{\text {th }}$ edn. Edinburgh: Churchill Livingstone 1999.

[5] Morris J, Spencer JA, Ambrose NS. MR imaging classification of perianal fistulas and its implications for patient management. Radiographics 2000;20(3):623-35.

[6] Khera PS, Badawi HA, Afifi AH. MRI in perianal fistulae. Indian J Radiol Imaging 2010;20(1):53-7.

[7] Halligan S, Stoker J. Imaging of fistula in ano. Radiology 2006;239(1):18-33.

[8] De Miguel CJ, del Salto LG, Rivas PF, et al. MR imaging evaluation of perianal fistulas: spectrum of imaging features. Radiographics 2012;32(1):175-94.

[9] Pearl RK, Andrews JR, Orsay CP, et al. Role of Seton in the management of anorectal fistulas. Dis Colon Rectum 1993;36(6):573-9. 


\section{Jemds.com}

[10] Schouten WR, van Vroonhoven TJ. Treatment of anorectal abscess with or without primary fistulectomy. Dis Colon Rectum 1991;34(1):60-3.

[11] Marks CG, Ritchie JK. Anal fistulas at St. Mark's hospital. Br J Surg 1977;64(2): 84-91.

[12] Seow-Choen SF, Nicholls RJ. Anal fistula. Br J Surg 1992;79(3):197-205.

[13] O'Malley RB, Al-Hawary MM, Kaza RK, et al. Rectal imaging: part 2, perianal fistula evaluation on pelvic MRI: What the radiologist needs to know? Am J Roentgenol 2012;199(1):W43-W53.

[14] Vasilevsky CA, Gordon PH. Results of treatment of fistula-in-ano. Dis Colon Rectum 1985;28(4):225-31.

[15] Parks AG, Gordon PH, Hardcastle JD. A classification of fistula-in-ano. Br J Surg 1976;63(1):1-12.

\section{Original Research Article}

[16] Romanes GJ. Thorax and abdomen. In: Cunningham's Manual of practical anatomy. Vol. 2. 15th edn. New York, NY: Medical Publications, Oxford University Press 1986.

[17] Gray H, Lewis WH. Gray's anatomy of the human body. $20^{\text {th }}$ edn. New York, NY: Bartleby 2000.

[18] Arderne J. Treatises of fistula in ano, hemorrhoids and clysters. From an early fifteenth century manuscript, translated by D'Arcy Power. London: Kegan Paul 1910.

[19] Zimmerman DDE. Diagnostic and treatment of transsphincteric perianal fistulas [Doctoral Thesis]. Rotterdam, The Netherlands: Erasmus University 2003. 